\title{
Profiles of Women With Fibromyalgia and Social Comparison Processes
}

\author{
M. Carmen Terol Cantero',2*, Abraham P. Buunk ${ }^{2}$, Victor Cabrera ${ }^{3}$, Miguel Bernabé ${ }^{4}$ and \\ Maite Martin-Aragón Gelabert ${ }^{1}$ \\ ${ }^{1}$ Departamento Ciencias del Comportamiento y Salud, Facultad Ciencias Sociosanitarias, Universidad Miguel Hernández, \\ Elche, Spain, ${ }^{2}$ Royal Netherlands Academy of Arts and Sciences (KNAW), Amsterdam, Netherlands, ${ }^{3}$ Departamento de \\ Psicología de la Salud, Universidad Miguel Hernández, Elche, Spain, ${ }^{4}$ Departamento de Psicología Social y de las \\ Organizaciones, Facultad de Psicología, Universidad Nacional de Educación a Distancia, Madrid, Spain
}

Background: Due to uncertainty regarding chronic pain in Fibromyalgia (FM) patients, there has been a growing interest in social comparison and its influence on emotional responses.

Aims: to analyze profiles in FM patients according to pain perception, social comparison strategies and anxiety and depression.

OPEN ACCESS

Edited by:

Sviatlana Kamarova

Curtin University, Australia

Reviewed by:

Simona Raimo,

University of Magna Graecia, Italy

Valentina Cuccio,

University of Messina, Italy

*Correspondence:

M. Carmen Terol Cantero

macarmen@umh.es

Specialty section:

This article was submitted to

Theoretical and Philosophical

Psychology,

a section of the journal

Frontiers in Psychology

Received: 13 September 2019

Accepted: 25 February 2020

Published: 13 March 2020

Citation:

Terol Cantero MC, Buunk AP,

Cabrera V, Bernabé $M$ and

Martin-Aragón Gelabert M (2020)

Profiles of Women With Fibromyalgia

and Social Comparison Processes.

Front. Psychol. 11:440.

doi: 10.3389/fpsyg.2020.00440
Methods: The sample consisted of $131 \mathrm{FM}$ outpatients (Mean age: $50.15, S D=11.1$ ). Two scales were used: the Social Comparison IIIness Scale and the Hospital Anxiety and Depression Scale.

Results: Two profiles were found by cluster analysis (K-means method): one (66\%) with a higher level of pain perception, anxiety and depression and greater use of upward contrast and downward identification social comparison; and another (34\%) with lower levels of pain perception, anxiety and depression and greater use of upward identification and downward contrast.

Conclusion: These profiles underline the interest in social comparison strategies and their role in FM.

Keywords: social comparison, fibromyalgia, patient profiles, anxiety, depression

\section{INTRODUCTION}

Fibromyalgia (FM) is a chronic disease that mainly affects women and is characterized by widespread musculoskeletal pain accompanied by various symptoms such as fatigue, stiffness, sleep disruption, physical symptoms (i.e., extreme sensitivity, headaches, irritable bowel syndrome, temporomandibular joint disorders) and high levels of anxiety and depression (Wolfe et al., 2010, 2013). The heterogeneity of these symptoms is one of the reasons why researchers have tried to analyze different patient profiles and their relationship with psychological adaptation. They present a "maladaptive profile" with higher levels of pain perception, anxiety and depression, in contrast to an "adaptive profile" with moderate/low levels of pain perception, anxiety and depression (Kurtze et al., 1998; Giesecke et al., 2003; Shuster et al., 2009; Calandre et al., 2011; Keller et al., 2011; Docampo et al., 2013). Anxiety and Depression could be important indicators for predicting a patient profile with a worse prognosis, more severe symptoms, pain perception and fewer functional abilities (Bennett, 2002; Thieme et al., 2004; De Souza et al., 2009; Calandre et al., 2011). However, 
cognitive processes are seen to have a fundamental role in reducing or dealing with anxiety and depression symptoms in FM (Rodero et al., 2010; Montesó-Curto et al., 2015; Peñacoba-Puente et al., 2015; Cabrera-Perona et al., 2017; Pastor-Mira et al., 2017).

According to the social comparison theory, lack of information and uncertainty can trigger cognitive processes of social comparison (Festinger, 1954). Indeed, chronic patients with higher uncertainty show more anxiety and depression symptoms and interest in social comparison (Butzer and Kuiper, 2006; Terol et al., 2007b, 2012, 2014; Terol-Cantero et al., 2015; Cabrera-Perona et al., 2017). These patients usually compare themselves with "others" or "referents" who are considered psychologically close or in a similar situation (e.g., same diagnosis) (Suls et al., 2002; Buunk and Gibbons, 2006; Corcoran et al., 2011). They compare "contents" such as symptoms, ways of coping or adjustment to chronic pain or illness (Butzer and Kuiper, 2006; Dibb and Yardley, 2006; Mussweiler et al., 2006; Jauregui-Lobera et al., 2010; Corcoran et al., 2011).

More specifically, the Identification-Contrast Model (Buunk and Ybema, 1997; Buunk and Gibbons, 2007) suggests that social comparison with "referents" either focusing on similarities with "others" who are better-off (upward identification), or focusing on contrast with "referents" who are worse-off (downward contrast) would create a positive affect (Buunk et al., 1990; Smith, 2000). However, social comparisons with better-off "others" while focusing on differences (upward contrast), or with worse-off "others" while perceiving similarities (downward identification) would lead to negative affect (Buunk et al., 1990; Smith, 2000). In chronic illness or pain, social comparison "strategies" such as upward identification and downward contrast have been associated with lower depression and better psychosocial adjustment (Van der Zee et al., 1996, 2000; Terol et al., 2012); and upward contrast or downward identification have been linked to higher depression and worse adjustment (Neugebauer et al., 2003; Terol et al., 2007b, 2014). In the same way, a few studies on FM have shown that upward identification or downward contrast strategies are related to lower pain perception and better mood (Affleck et al., 2000; Terol et al., 2014; Cabrera-Perona et al., 2017) and upward contrast or downward identification are associated with higher levels of anxiety and depression, and worse psychological adjustment (Affleck et al., 2000; Groothof and Scholtes, 2007; Terol et al., 2014; Cabrera-Perona et al., 2017).

In the context of the above, the aim of this study was to analyze the profiles of women with FM who share common characteristics based on a set of assessed variables: pain perception, social comparison processes (strategies, referents, and contents) and anxiety and depression.

\section{MATERIALS AND METHODS}

\section{Sample}

The sample consisted of 131 Spanish female outpatients interviewed at San Vicente del Raspeig Hospital (FM Department). The mean age was $50.15(S D=11.14)$. Mean time since diagnosis was 4.32 years $(S D=4.99) .68 .70 \%$ of the participants were married and $31.3 \%$ were single, separated-divorced or widows. Educational level was primary and secondary school (77\%), higher education (10.7\%), and $\mathrm{read} /$ write $(12.3 \%)$. Inclusion criteria were: (1) FM diagnosis re-confirmed by the American College of Rheumatology (ACR) criteria (Wolfe et al., 2010) upon their arrival at the FM Department, (2) aged over 18, (3) no previous psychiatric diagnosis (4) ability to understand questionnaires, (5) informed consent to participate in the study.

\section{Assessments}

In addition to collecting information about age, marital status, educational level and time since diagnosis, the following scales were used to assess the variables used in the study:

Pain perception Visual Analog Scale (VAS: Aliaga-Font, 2009) was used to assess: current pain, average pain last week, and maximum pain last week. Patients had to mark their pain perception for each of the three times on the VAS $(0=$ no pain to $10=$ worst imaginable pain).

Social Comparison Process in Illness scale (adapted from Van der Zee et al. (2000) by Terol et al. (2007a, 2014). This scale includes 18 -ítems with a Likert response-scale ( 1 = never; $5=$ very often) grouped into three subscales: Social Comparison Strategies, Social Comparison Referents, and Social Comparison Contents. Three items are included in each of the four Social comparison strategies: upward identification ( $a=0.89)$, upward contrast $(a=0.84)$, downward identification $(a=0.93)$, and downward contrast $(a=0.75)$. The referents subscale includes three items ("others" with similar health problems, with different health problems, and with no health problems) and contents also includes three items (symptoms, mood, and physical activity). Higher scores show a greater frequency in patients' use of social comparison strategies, referents or contents.

Hospital Anxiety and Depression Scale (HADS: Zigmond and Snaith, 1983; Spanish adaptation by Terol et al., 2007a). This is a 14-item scale consisting of two 7-item subscales: Anxiety and Depression. Responses are given on Likert scales from 0 to 3 with a 0-21 range for each subscale. Higher scores show higher levels of anxiety and/or depression. Internal consistency for this study, HADS - Anxiety $\alpha=0.80$, HADS - Depression $\alpha=0.85$.

\section{Procedure}

This was a cross-sectional study with a non-probability convenience sample. After the Hospital Ethics Committee's approval of the study, we selected 152 newly admitted outpatients with FM diagnosis. Patients were informed of the study and they signed an informed consent. 13 of these patients refused to participate and eight did not meet the inclusion criteria. Subsequently, 131 outpatients were interviewed by a psychologist in sessions lasting from 20 to $30 \mathrm{~min}$.

\section{Statistical Analysis}

The software IBM SPSS v.22 was used for the statistical analysis, and the Kolmogorov-Smirnov test was carried out for distribution of scores (HADS: $D=0.057 ; p=0.20$; Social Comparison Processes in Illness Scale: $D=1.24 ; p=0.000$ ). Means and frequencies were used for the Descriptive Analyses. 
For Patients' Profiles, an iterative K-means cluster analysis (non-hierarchical method) was performed to identify subgroups $(K=2)$ and differences were analyzed by ANOVA (F-Fisher with $p<0.05$ were accepted). Prior to clustering, multicollinearity was assessed (VIFs $<6$ ). Contingency tables and $\chi^{2}$ statistics were used for the sample distribution "case" / "non-case" according to the HADS and inclusion in either of the profiles. In FM, specific cut-off points for those considered "cases" were recently fixed at +12 for the HADS-Anxiety and HADS-Depression subscales (see Cabrera et al., 2015).

\section{RESULTS}

\section{Descriptive Analysis}

Table 1 shows means, standard deviations and range scores for all study variables. Frequency in patient's use of Social Comparison strategies referents or contents are presented in Table 2.

Pain perception VAS mean scores were above five points. Anxiety and Depression mean scores were $13.71(S D=4.00)$ and $10.73(S D=4.64)$, respectively.

For social comparison, $75.6 \%$ of patients used upward contrast strategies with high frequency, which was the most used strategy (see Table 2). In addition, $52.6 \%$ of our sample compared themselves with other referents with a similar health problem $(M=3.37 ; S D=1.35$; Range $=1-5)$ and compared contents

TABLE 1 | Descriptive analysis: Means, standard deviations, and range scores for all variables.

\begin{tabular}{|c|c|c|c|}
\hline & \multicolumn{3}{|c|}{ Total sample = 131} \\
\hline & $M$ & $S D$ & Range \\
\hline \multicolumn{4}{|c|}{$\begin{array}{l}\text { Pain perception Visual Analog } \\
\text { Scale }\end{array}$} \\
\hline Current pain & 5.48 & 1.56 & $0-10$ \\
\hline Last week average pain & 6.58 & 1.56 & $0-10$ \\
\hline Maximum pain last week & 7.18 & 1.44 & $0-10$ \\
\hline \multicolumn{4}{|c|}{$\begin{array}{l}\text { Social Comparison Processes } \\
\text { in IIIness Scale Strategies }\end{array}$} \\
\hline Upward identification & 9.31 & 2.97 & $3-15$ \\
\hline Upward contrast & 11.30 & 3.11 & $3-15$ \\
\hline Downward identification & 9.98 & 3.63 & $3-15$ \\
\hline Downward contrast & 9.10 & 3.01 & $3-15$ \\
\hline \multicolumn{4}{|l|}{ Referents } \\
\hline Similar health problems & 3.37 & 1.35 & $1-5$ \\
\hline Different health problems & 2.98 & 1.24 & $1-5$ \\
\hline No health problems & 3.02 & 1.49 & $1-5$ \\
\hline \multicolumn{4}{|l|}{ Contents } \\
\hline Symptoms & 4.36 & .81 & $1-5$ \\
\hline Mood & 3.89 & 1.05 & $1-5$ \\
\hline Physical activity & 4.02 & 1.22 & $1-5$ \\
\hline \multicolumn{4}{|l|}{$\begin{array}{l}\text { Hospital Anxiety and } \\
\text { Depression Scale }\end{array}$} \\
\hline Anxiety & 13.71 & 4 & $0-21$ \\
\hline Depression & 10.73 & 4.64 & $0-21$ \\
\hline
\end{tabular}

M, mean; SD, Standard Deviation.
TABLE 2 | Descriptive analysis: Frequency in patient's use of social comparison strategies referents or contents according to three categories $\left(^{\star}\right)$.

\begin{tabular}{lccc}
\hline & \multicolumn{3}{c}{ Total sample = 131 } \\
\cline { 2 - 4 } & $\begin{array}{c}\text { Low } \\
\text { frequency }\end{array}$ & $\begin{array}{c}\text { Medium } \\
\text { frequency }\end{array}$ & $\begin{array}{c}\text { High } \\
\text { frequency }\end{array}$ \\
\hline Social Comparison Strategies & & & $42 \%$ \\
Upward identification & $18.3 \%$ & $39.7 \%$ & $75.6 \%$ \\
Upward contrast & $9.9 \%$ & $14.5 \%$ & $56.5 \%$ \\
Downward identification & $19.1 \%$ & $24.4 \%$ & $45 \%$ \\
Downward contrast & $20.6 \%$ & $34.4 \%$ & $52.6 \%$ \\
Social Comparison Referents & & & $35.1 \%$ \\
Similar health problems & $26.2 \%$ & $22.1 \%$ & $42 \%$ \\
Different health problems & $33.6 \%$ & $31.3 \%$ & $85.5 \%$ \\
No health problems & $37.4 \%$ & $20.6 \%$ & $66.4 \%$ \\
Social Comparison Contents & & & $71.7 \%$ \\
Symptoms & $2.3 \%$ & $12.2 \%$ & $22.1 \%$ \\
Mood & $11.5 \%$ & $13 \%$ & \\
Physical Activity & $15.3 \%$ & & \\
\hline
\end{tabular}

*Likert response-scale ( 1 = never; $5=$ very often) grouped into three categories of frequency: Low = 1-2; Medium = 3; and High = 4-5.

such as illness symptoms with high frequency (85.5\%) $(M=4.36$; $S D=0.081$; Range $=1-5)($ See Tables 1, 2).

\section{Patient Profiles}

As shown in Table 3, K-means cluster analysis and differences by ANOVA were performed with the following variables: pain perception, social comparison (strategies, referents and contents), anxiety and depression. The cluster analysis identified two groups of women. Cluster 1 includes 86 patients (65.6\%) showing higher pain perception $(p<0.001)$, greater use of upward contrast and downward identification strategies $(p<0.001)$, comparison with referents with different and similar health problems $(p<0.05)$ and contents such as illness symptoms and $\operatorname{mood}(p<0.05)$, as well as higher levels of anxiety and depression $(p<0.001)$. Cluster 2 includes 45 patients $(34.3 \%)$ showing lower pain perception $(p<0.001)$, greater use of upward identification $(p<0.001)$, and downward contrast $(p<0.05)$, lower frequency of comparison with referents or contents $(p<0.05)$, as well as lower anxiety and depression $(p<0.001)$.

Finally, we show the contingency table analysis and chi-square test in order to match patient's profiles (Cluster 1,2) according cut-off points fixed for the HADS (Table 4). Of the sample distribution, $76.9 \%$ of anxiety cases and $85.2 \%$ of depression cases were classified according to the HADS cut-off points (HADS Anxiety and HADS - Depression $\geq+12$ ) for FM in Cluster 1 .

\section{DISCUSSION}

This study illustrates the role of social comparison processes in FM patients. We found that upward contrast and downward identification were the strategies most used by patients with FM. They also compare themselves with others (referents) on "similar health problems" and on contents such as "symptoms." 
TABLE 3 | Patient profiles: Cluster analysis and differences by ANOVA.

\begin{tabular}{|c|c|c|c|c|}
\hline & $\begin{array}{l}\text { Cluster } 1 \\
(n=86) \\
M \pm S D\end{array}$ & $\begin{array}{c}\text { Cluster } 2 \\
(n=45) \\
M \pm S D\end{array}$ & $\mathbf{F}$ & Sig \\
\hline \multicolumn{5}{|c|}{ Pain Perception Visual Analog Scale } \\
\hline Current pain & $6.06 \pm 1.15$ & $4.36 \pm 1.64$ & 6.114 & ** \\
\hline Last week average pain & $7.22 \pm 1.25$ & $5.32 \pm 1.33$ & 8.046 & ** \\
\hline Maximum pain last week & $7.78 \pm 1.02$ & $6.02 \pm 1.42$ & 7.285 & ** \\
\hline \multicolumn{5}{|c|}{ Social Comparison Processes in IIIness Scale Strategies } \\
\hline Upward identification & $8.36 \pm 2.64$ & $11.18 \pm 2.72$ & -5.708 & ** \\
\hline Upward contrast & $12.65 \pm 1.97$ & $8.77 \pm 3.27$ & 7.226 & ** \\
\hline Downward identification & $11.01 \pm 3.43$ & $8.00 \pm 3.23$ & 4.829 & ** \\
\hline Downward contrast & $8.55 \pm 2.66$ & $10.16 \pm 3.40$ & -2.748 & . \\
\hline \multicolumn{5}{|l|}{ Referents } \\
\hline Similar health problems & $3.57 \pm 1.38$ & $3.00 \pm 1.24$ & 2.308 & - \\
\hline Different health problems & $3.21 \pm 1.26$ & $2.52 \pm 1.11$ & 3.063 & * \\
\hline No health problems & $3.15 \pm 1.52$ & $2.75 \pm 1.43$ & 1.450 & (ns \\
\hline \multicolumn{5}{|l|}{ Contents } \\
\hline Symptoms & $4.50 \pm 0.75$ & $4.07 \pm .87$ & 2.941 & r \\
\hline Mood & $4.09 \pm 0.99$ & $3.50 \pm 1.09$ & 3.124 & 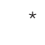 \\
\hline Physical Activity & $3.91 \pm 1.31$ & $4.23 \pm 1.01$ & -1.545 & (ns \\
\hline \multicolumn{5}{|c|}{ Hospital Anxiety and Depression Scale } \\
\hline Anxiety & $15.30 \pm 3.54$ & $10.70 \pm 3.13$ & 7.277 & ** \\
\hline Depression & $12.50 \pm 4.04$ & $7.48 \pm 3.75$ & 6.875 & ** \\
\hline
\end{tabular}

Pain perception, social comparison (strategies, referents, and contents) and anxiety and depression. $M$, mean; $S D$, Standard Deviation; F-Fisher with ${ }^{*} p \leq 05 ;{ }^{* *}$ : $p \leq 001 ;$ (ns), non-significant.

TABLE 4 | Patient profiles: Contingency table analysis and Chi-Square Test.

\begin{tabular}{lcccc}
\hline & $\begin{array}{c}\text { Anxiety- } \\
(\boldsymbol{n}=\mathbf{2 7})\end{array}$ & $\begin{array}{c}\text { Anxiety+ } \\
(\boldsymbol{n}=\mathbf{1 0 4})\end{array}$ & $\begin{array}{c}\text { Depression- } \\
(\boldsymbol{n}=\mathbf{7 0})\end{array}$ & $\begin{array}{c}\text { Depression+ } \\
(\boldsymbol{n}=\mathbf{6 1 )}\end{array}$ \\
\hline Cluster 1. $(n=86)$ & $23.1 \%$ & $76.9 \%$ & $50 \%$ & $85.2 \%$ \\
Cluster 2. $(n=45)$ & $76.9 \%$ & $23.1 \%$ & $50 \%$ & $14.8 \%$ \\
& $100 \%$ & $100 \%$ & $100 \%$ & $100 \%$ \\
& $\chi^{2}=26.934^{\star \star}$ & $\chi^{2}=18.710^{\star \star}$ & \\
\hline
\end{tabular}

Cluster 1, 2 according cut-off points for the HADS. Anxiety-: score < 12; Anxiety+: score $\geq 12$; Depression-: score $<12$; Depression+: score $\geq 12 . \chi^{2:}$ : Chi-square; ${ }^{* *} p \leq 001$.

These results coincide with another recent study on FM (Terol et al., 2007b, 2012) but differ from findings in other chronic patients (rheumatoid arthritis or cancer patients) who used upward identification and/or downward contrast more often (Blalock et al., 1990; De Vellis et al., 1990; Dibb and Yardley, 2006; Terol et al., 2007b, 2012). The findings regarding the profiles in FM patients revealed two different subgroups. One of them was a "maladaptive" profile, including women with higher levels of pain perception, anxiety and depression and more frequent "unfavorable" social comparison strategies (upward contrast and downward identification). The other group, or more "adaptive" profile, included women who showed moderate levels of pain perception, with a lower level of anxiety and depression and more frequent "favorable" social comparison strategies (upward identification and downward contrast). These profiles are consistent with other studies that have correlated these variables in the same way (Terol et al., 2012; CabreraPerona et al., 2017) or have identified similar groups of patients in FM (Giesecke et al., 2003; De Souza et al., 2009; Calandre et al., 2011; Keller et al., 2011; Docampo et al., 2013). Giesecke et al. (2003) proposed three profiles, one of which shows moderate anxiety / depression and less pain, while another presents a higher level of anxiety / depression and pain. Using the FIQ (FM Impact Questionnaire: Burckhardt et al., 1991) other researchers also report that pain and stiffness appeared in all profiles, but psychological stress (anxiety and depression) was the differentiating feature between these profiles (De Souza et al., 2009; Calandre et al., 2011). According to this, in our sample, $76.9 \%$ and $85.2 \%$, classified as "cases" of anxiety and depression, fitted into the "maladaptive" profile (HADS $\geq+12$ : Cabrera et al., 2015). This leads us to turn our attention toward FM profiles, but in the context of social comparison processes and their negative emotional consequences (Bair et al., 2003).

\section{Research and Clinical Implications}

Our results are consistent with the Identification-Contrast Model (Buunk and Ybema, 1997) applied in FM or chronic illness, where frequency of upward contrast and downward identification strategies were related to psychological distress (i.e., anxiety and depression), and poor subjective well-being, quality of life or adjustment (Buunk and Gibbons, 2006; Groothof and Scholtes, 2007; Arigo et al., 2012; Terol et al., 2014; Cabrera-Perona et al., 2017). In particular, this study provides useful information about cognitive processes in women with FM, who use different social comparison strategies together with other relevant "comorbidity" symptoms: perception of pain and anxiety and depression. Lastly, this study supports some approaches toward improving more "adaptive" profiles and useful cognitive processes: (a) identifying strategies such as upward contrast or downward identification in order to change them, (b) encouraging positive thought thorough the use of "favorable" comparisons strategies (downward contrast and upward identification), which would act as a buffer to pathologic emotions and increase a better adjustment to chronic illness (Arigo et al., 2012; Terol et al., 2014; Cabrera-Perona et al., 2017), and (c) motivating the comparison processes with referents or "models" that provide adaptive strategies for coping and enhancing their subjective well-being.

\section{Limitations}

The first limitation of this study is that all the participants are female. However, FM research is generally focused on women who suffer from this chronic pain. The reason why the sample consists of only women corresponds to the justified prevalence of FM diagnosis in women, as noted: the preponderance of FM in women versus men with an approximate ratio of 9:1 (Wolfe et al., 1995; Mas et al., 2008; Katz et al., 2010). Other limitations are related to the size of the sample and selection by accessibility. Although a larger sample would be beneficial, Jager et al. (2017) consider that homogeneous convenience samples (sociodemographic or clinical factors of the general population) 
can be a positive alternative. In this sense, we verified that our sample features were similar to those found in other FM studies.

The cluster analysis is a cross-sectional and exploratory method. Longitudinal studies and regression analysis could further clarify the role of social comparison as an antecedent or consequence of emotional responses (i.e., anxiety and / or depression). Finally, it would be very useful to ascertain the severity of chronic symptoms, uncertainty, anxiety and depression and how they change at different stages of illness and in health settings (primary care level, FM patient associations).

\section{DATA AVAILABILITY STATEMENT}

The datasets generated for this study are available on request to the corresponding author.

\section{ETHICS STATEMENT}

The studies involving human participants were reviewed and approved by the San Vicente del Raspeig Hospital Ethics

\section{REFERENCES}

Affleck, G., Tennen, H., Urrows, S., Higgins, P., and Abeles, M. (2000). Downward comparisons in daily life with chronic pain: dynamic relations with pain intensity and mood. J. Soc. Clin. Psychol. 19, 499-518. doi: 10.1521/jscp.2000. 19.4.499

Aliaga-Font, L. (2009). Tratamiento del Dolor: Teoría y Práctica. Barcelona: Permanyer.

Arigo, D., Suls, J., and Smyth, J. M. (2012). Social comparisons and chronic illness: research synthesis and clinical implications. Health Psychol. Rev. 8, 154-214. doi: 10.1080/17437199.2011.634572

Bair, M. J., Robinson, R. L., Katon, W., and Kroenke, K. (2003). Depression and pain comorbidity: a literature review. Arch. Intern. Med. 163, 2433-2445.

Bennett, R. M. (2002). Rational management of fibromyalgia. Rheum. Dis. Clin. North Am. 28, 13-25.

Blalock, S. J., Afifi, R. A., De Vellis, B. M., Holt, K., and De Vellis, R. F. (1990). Adjustment to rheumatoid arthritis: the role of social comparison processes. Health Educ. Res. 5, 361-370. doi: 10.1093/her/5.3.361

Burckhardt, C. S., Clark, S. R., and Bennett, R. M. (1991). The fibromyalgia impact questionnaire: development and validation. J. Rheumatol. 18, 728-733.

Butzer, B., and Kuiper, N. A. (2006). Relationships between the frequency of social comparisons and self-concept clarity, intolerance of uncertainty, anxiety, and depression. Pers. Individ. Diff. 41, 167-176. doi: 10.1016/j.paid.2005.12.017

Buunk, A. P., and Gibbons, F. X. (2007). Social comparison: the end of a Theory and the emergence of a field. Organ. Behav. Hum. Decis. Process. 102, 3-21. doi: 10.1016/j.obhdp.2006.09.007

Buunk, B. P., Collins, R., Taylor, S., VanYperen, N., and Dakof, G. (1990). The affective consequences of social comparison: either direction has its ups and downs. J. Pers. Soc. Psychol. 59, 1238-1249. doi: 10.1037/0022-3514.59.6.1238

Buunk, B. P., and Gibbons, F. X. (2006). "Social comparison orientation: a new perspective on those who do and those who don't compare with others," in Social comparison and Social Psychology: Understanding Cognition, Intergroup Relations and Culture, ed. H. Guimond, (Cambridge, MA: University Press), 15-32. doi: 10.1017/cbo9780511584329.003

Buunk, B. P., and Ybema, J. F. (1997). "Social comparisons and occupational stress: the identification-contrast model," in Health, Coping, and Well-being: Perspectives from Social Comparison Theory, eds B. P. Buunk, and F. X. Gibbons, (Mahwah, NJ: Lawrence Erlbaum Publishers), 359-388.
Committee. The patients/participants provided their written informed consent to participate in this study.

\section{AUTHOR CONTRIBUTIONS}

All authors have contributed significantly to the article. VC and MT designed the study and protocol. MB and VC carried out the data analysis and results. MM-A, AB, and MT wrote and reviewed the original draft.

\section{FUNDING}

This research was supported by the FPU National Plan, Spanish Ministry of Education (MEC) (2010 Call. Grant reference AP2010-1870).

\section{ACKNOWLEDGMENTS}

We thank the participants and health professionals from San Vicente del Raspeig Hospital.

Cabrera, V., Martín-Aragón, M., Terol, M. C., Núñez, R., and Pastor, M. A. (2015). Escala de ansiedad hospitalaria en fibromialgia: análisis de sensibilidad y especificidad. Ter. Psicol. 33, 181-193. doi: 10.4067/S0718-48082015000300003

Cabrera-Perona, V., Buunk, A. P., Terol-Cantero, M. C., Quiles-Marcos, Y., and Martín-Aragón, M. (2017). Social comparison processes and catastrophising in fibromyalgia: a path analysis. Psychol. Health 32, 745-764. doi: 10.1080/ 08870446.2017.1307370

Calandre, E. P., Garcia-Carrillo, J., Garcia-Leiva, J. M., Rico-Villademoros, F., Molina-Barea, R., and Rodriguez-Lopez, C. M. (2011). Subgrouping patients with fibromyalgia according to the results of the fibromyalgia impact questionnaire: a replication study. Rheumatol. Int. 31, 1555-1559. doi: 10.1007/ s00296-010-1521-3

Corcoran, K., Cruisius, J., and Mussweiler, T. (2011). "Social comparison: motives, standards and mechanisms," in Theories in Social Psychology, ed. D. Chadee, (Oxford, UK: Wiley-Blackwell), 119-139.

De Souza, J. B., GoVaux, P., Julien, N., Potvin, S., Charest, J., and Marchand, S. (2009). Fibromyalgia subgroups: profiling distinct subgroups using the fibromyalgia impact questionnaire. A preliminary study. Rheumatol. Int. 29, 509-515. doi: 10.1007/s00296-008-0722-5

De Vellis, R. F., Holt, K., Renner, B. R., and Blalock, S. J. (1990). The relationship of social comparison to rheumatoid arthritis symptoms and affect. Basic Appl. Soc. Psychol. 11, 11-18. doi: 10.1207/s15324834basp1101_1

Dibb, B., and Yardley, L. (2006). Factors important for the measurement of social comparison in chronic illness: a mixed-methods study. Chronic Illness 2, 219-230. doi: 10.1177/17423953060020030301

Docampo, E., Collado, A., Escaramís, G., Carbonell, J., Rivera, J., Vidal, J., et al. (2013). Cluster analysis of clinical data identifies fibromyalgia subgroups. PLoS One 8:e74873. doi: 10.1371/journal.pone.0074873

Festinger, L. (1954). A theory of social comparison processes. Hum. Relat. 7, 117-140. doi: 10.1177/001872675400700202

Giesecke, T., Williams, D. A., Harris, R. E., Cupss, T. R., Tian, X., Tian, T. X., et al. (2003). Subgrouping of fibromyalgia patients on the basis of pressure-pain thresholds and psychological factors. Arthritis Rheumathoid 48, 2916-2922. doi: 10.1002/art.11272

Groothof, H. A. K., and Scholtes, R. (2007). Are support groups beneficial for fibromyalgia patients? The negative effects of social comparison for those who want it most Abstracts. Health. Psychol. Rev. 1, 9-309. doi: 10.1080/ 17437190701472504 
Jager, J., Putnick, D. L., and Bornstein, M. H. (2017). More than just convenient: the scientific merits of homogeneous convenience samples. Monogr. Soc. Res. Child Dev. 82, 13-30. doi: 10.1111/mono.12296

Jauregui-Lobera, I., Garrido, O., Santiago-Fernández, M. J., and Alvarez-Bautista, E. (2010). Social comparison as coping strategy among caregivers of eating disordes patients. J. Psychiatr. Mental Health Nurs. 17, 775-782. doi: 10.1111/ j.1365-2850.2010.01611.x

Katz, J. D., Mamyrova, G., Guzhva, O., and Furmark, L. (2010). Gender bias in diagnosing fibromyalgia. Gender Med. 7, 19-27. doi: 10.1016/j.genm.2010. 01.003

Keller, D., De Gracias, M. Y., and Cladellas, R. (2011). Subtipos de pacientes con fibromialgia, características psicopatológicas y calidad de vida. Actas Esp. Psiquiatr. 39, 273-279.

Kurtze, N., Gunderson, K. T., and Svebak, S. (1998). The role of anxiety and depression in fatigue and pattern of pain among subgroups of fibromyalgia patients. Br. J. Med. Psychol. 71, 185-194. doi: 10.1111/j.2044-8341.1998. tb01379.x

Mas, A. J., Carmona, L., Valverde, M., Ribas, B., and Episer Study Group. (2008). Prevalence and impact of fi bromyalgia on function and quality of life in individuals from the general population: results from a nationwide study in Spain. Clin. Exp. Rheumatol 26, 519-526.

Montesó-Curto, P., García-Martínez, M., Gómez-Martínez, C., Ferré-Almo, S., Panisello-Chavarria, M. L., Genís, S. R., et al. (2015). Effectiveness of three types of interventions in patients with fibromyalgia in a region of Southern Catalonia. Pain. Manag. Nurs. 16, 642-652. doi: 10.1016/j.pmn.2015. 01.006

Mussweiler, T., Ruter, K., and Epstude, K. (2006). "The why, who, and how of social comparison: a social-cognition perspective," in Social Comparison and Social Psychology: Understanding Cognition, Intergroup Relations and Culture, ed. H. Guimond, (Cambridge, MA: University Press), 33-54. doi: 10.1017/ cbo9780511584329.004

Neugebauer, A., Katz, P. P., and Pasch, L. A. (2003). Effect of valued activity disability, social comparisons, and satisfaction with ability on depressive symptoms in rheumatoid arthritis. Health Psychol. 22, 253-262. doi: 10.1037/ 0278-6133.22.3.253

Pastor-Mira, M. Á, López-Roig, S., Peñacoba, C., and Lledó-Boyer, A. (2017). Viabilidad de la utilización de intenciones de implementación para aumentar el ejercicio físico andando en mujeres con fibromialgia / Feasibility of using implementation intentions to increase physical exercise walking in women with fibromyalgia. Rev. Soc. Esp. Dolor 25(Suppl. 1), 4-13. doi: 10.20986/resed.2017. $3601 / 2017$

Peñacoba-Puente, C., Velasco-Furlong, L., Ecija-Gallardo, C., Cigarán- Méndez, M., Bedmar-Cruz, D., and Fernández de las Peñas, C. (2015). Self-Efficacy and affect as mediators-between pain dimensions and emotional symptoms and functional limitation in women with fibromyalgia. Pain Manag. Nurs. 16, 60-68. doi: 10.1016/j.pmn.2014.04.005

Rodero, B., Casanueva, B., Garcia-Campayo, J., Roca, M., Magallon, R., and Lopez del Hoyo, Y. (2010). Stages of chronicity in fibromyalgia and pain catastrophising: a cross-sectional study. BMC Musculoskelet. Disord. 11:251. doi: 10.1186/1471-2474-11-251

Shuster, J., McCormack, J., Pillai-Riddell, R., and Toplak, M. E. (2009). Understanding the psychosocial profile of women with fibromyalgia syndrome. Pain Res. Manag. 14, 239-245. doi: 10.1155/2009/134808

Smith, R. (2000). "Assimilative and contrastive emotional reactions to upward and downward social comparisons," in Handbook of Social Comparison: Theory and Research, eds J. Suls, and L. Wheeler, (New York, NY: Plenum), 173-200. doi: 10.1007/978-1-4615-4237-7_10
Suls, J. M., Martin, R., and Wheeler, L. (2002). Social comparison: why, with whom, and with what effect? Curr. Dir. Psychol. Sci. 11, 159-163. doi: 10.1111/14678721.00191

Terol, M. C., Lledó, A., Quiles, Y., and Martín-Aragón, M. (2014). Adaptation and validation of the Spanish version of the social comparison scale in chronic illness patients. J. Health Psychol. 20, 1474-1482. doi: 10.1177/ 1359105313514284

Terol, M. C., López-Roig, S., Rodríguez-Marín, J., Martín-Aragón, M., Pastor, M. A., and Reig, M. T. (2007a). Propiedades psicométricas de la escala hospitalaria de ansiedad y depresión (HAD) en población española. Ansiedad Estrés 13, 163-176.

Terol, M. C., Neipp, M. C., Lledó-Boyer, A., Pons, N., and Bernabé, M. (2012). Comparación social y variables psicosociales relacionadas: una revisión de cáncer y dolor crónico. An. Psicol. 28, 327-337. doi: 10.6018/analesps.28.2. 148931

Terol, M. C., Pons, N., Neipp, M. C., Rodríguez-Marín, J., Buunk, A., MartínAragón, M., et al. (2007b). Estrategias de comparación social y resultados en salud: un estudio de adaptación y evaluación en muestra española de pacientes crónicos. Cuadernos Med. Psicosom. Psiquiatr. Enlace 84, 19-32.

Terol-Cantero, M. C., Cabrera-Perona, V., and Martín-Aragón, M. (2015). Revisión de estudios de la Escala de Ansiedad y Depresión Hospitalaria (HAD) en muestras españolas. An. Psicol. 31, 494-503. doi: 10.6018/analesps.31.2. 172701

Thieme, K., Turk, D. C., and Flor, H. (2004). Comorbid depression and anxiety in fibromyalgic syndrome: relationship to somatic and psychosocial variables. Psychos. Med. 66, 837-844. doi: 10.1097/01.psy.0000146329.63158.40

Van der Zee, K., Buunk, B. P., DeRuiter, J. H., Tempelaar, R., VanSonderen, E., and Sanderman, R. (1996). Social comparison and the subjective well-being of cancer patients. Basic Appl. Soc. Psychol. 18, 453-468.

Van der Zee, K., Buunk, B. P., Sanderman, R., Botke, G., and Van den Bergh, F. (2000). Social comparison and coping with cancer treatment. Pers. Individ. Diff. 28, 17-34. doi: 10.1016/S0191-8869(99)00045-8

Wolfe, F., Brähler, E., Hinz, A., and Häuser, W. (2013). Fibromyalgia prevalence, somatic symptom reporting, and the dimensionality of polysymptomatic distress: results from a survey of the general population. Arthritis Care Res. 65, 777-785. doi: 10.1002/acr.21931

Wolfe, F., Clauw, D. J., Fitzcharles, M. A., Goldenberg, D. L., Katz, R. S., Mease, P., et al. (2010). The American College of Rheumatology preliminary diagnostic criteria for fibromyalgia and measurement of symptom severity. Arthritis Care Res. 62, 600-610. doi: 10.1002/acr.20140

Wolfe, F., Ross, K., Anderson, J., Russell, I. J., and Hebert, L. (1995). The prevalence and characteristics of fibromyalgia in the general population. Arthritis Rheumatol. 38, 19-28. doi: 10.1002/art.1780380104

Zigmond, A., and Snaith, R. (1983). The hospital anxiety and depression scale. Acta Psychiatr. Scand. 67, 361-370. doi: 10.1111/j.16000447.1983.tb09716.x

Conflict of Interest: The authors declare that the research was conducted in the absence of any commercial or financial relationships that could be construed as a potential conflict of interest.

Copyright (c) 2020 Terol Cantero, Buunk, Cabrera, Bernabé and Martin-Aragón Gelabert. This is an open-access article distributed under the terms of the Creative Commons Attribution License (CC BY). The use, distribution or reproduction in other forums is permitted, provided the original author(s) and the copyright owner(s) are credited and that the original publication in this journal is cited, in accordance with accepted academic practice. No use, distribution or reproduction is permitted which does not comply with these terms. 